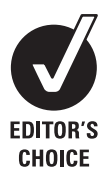

${ }^{1}$ Flinders University/Flinders Medical Centre, Bedford Park, Australia; ${ }^{2}$ The University of Melbourne, Department of Medicine, St Vincent's Hospital, Fitzroy, Australia; ${ }^{3}$ Sanofi Aventis Australia; ${ }^{4}$ Concord Hospital, Department of Cardiology, Hospital Road, Concord, Australia

Correspondence to: Professor D P Chew, Flinders University, Flinders Drive, Bedford Park, South Australia, 5042 Australia;

derek.chew@flinders.edu.au

Accepted 28 July 2009

Published Online First

6 August 2009

\title{
Potential survival gains in the treatment of myocardial infarction
}

\author{
D P Chew, ${ }^{1}$ L T Huynh, ${ }^{1}$ D Liew, ${ }^{2}$ C Astley, ${ }^{1}$ A Soman, ${ }^{3}$ D Brieger ${ }^{4}$
}

\author{
ABSTRACT \\ Objectives: To evaluate the potential impact of complete \\ implementation of guideline recommendations in myo- \\ cardial infarction (MI) care, and contrast this with new \\ innovations.
}

Design: Modelling of potential events prevented from literature-based treatment effects and observed guideline recommendation utilisation rates.

Setting: Hospital-based care.

Participants: Nationwide registry of 1630 patients with $\mathrm{Ml}$ adjusted for age, gender and GRACE score extrapolated to a population of 10000 patients.

Interventions: Literature-based efficacy estimates associated with guideline-recommended treatments and a putative treatment providing a $10-30 \% 12$-month event reduction.

Main outcome measures: Mortality and recurrent $\mathrm{Ml}$ or stroke by 30 days and 30 days to 12 months.

Results: Adjusted-mortality rates for optimally managed patients with ST-segment MI (STEMI) and non-ST-

segment MI (NSTEMI) to 30 days were $0.6 \%$ and $2.5 \%$, respectively. Adjusted mortality from 30 days to

12 months was $1.8 \%$ among optimally managed patients. No reperfusion occurred in $31 \%$ of patients with STEMI. Fewer than four guideline treatments were prescribed in $26 \%$ of patients at discharge. Compared with in-hospital care, better application of secondary prevention treatments provided the greater absolute gains (STEMI 23 lives/10 000 patients by 30 days, NSTEMI 43 lives/ 10000 by 30 days and secondary prevention 104 lives/ 10000 by 12 months). A putative novel treatment reducing mortality by $30 \%$ among optimally managed patients would save a further 4 lives/10 000 by 12 months.

Conclusions: Potential gains from improved clinical effectiveness in $\mathrm{Ml}$ care are likely to compare favourably with benefits achieved though innovations, and should inform priorities in research and implementation strategies for improving MI outcomes.

In recent decades, many advances have occurred in the management of myocardial infarction (MI). These include emergent percutaneous coronary intervention (PCI) for reperfusion; potent antithrombotic agents; and HMG-CoA reductase inhibition. Collectively, these treatments have led to a decline in MI mortality and morbidity, and are advocated in clinical guidelines. ${ }^{12}$ The drive for innovation continues in areas including device technologies, myocardial protection and stem cell technology. ${ }^{3-5}$

Yet, current studies frequently combine fatal and non-fatal outcomes or employ a non-inferiority design in recognition of a slowing in the reduction in MI mortality through innovation. In this context the incomplete application of evidence-based treatments within in-hospital care of acute coronary syndrome (ACS) has also been documented and is associated with suboptimal clinical outcomes in a number of studies. ${ }^{6-8}$ Similarly, delays in hospital presentation and poor access among many patients are associated with increased adverse events and mortality. ${ }^{9}$ Non-adherence with secondary prevention treatments is also associated with late mortality that could be prevented. ${ }^{10}$

Consequently, we explored the potential gains in lives saved and events prevented through optimisation of each of these areas within the context of current Australian practice in the management of MI and contrasted these with the potential gains from putative novel treatments. Such an analysis may provide perspective for focusing efforts towards improving clinical outcomes.

\section{METHODS}

\section{Study design and patient population}

To evaluate the potential impact of more thorough application of proven evidence-based care, we developed a model that incorporated current utilisation rates in a nationwide audit of current ACS management and treatment effects for various treatments established in large-scale randomised clinical trials or meta-analyses.

Details of the Acute Coronary Syndrome Prospective Audit (ACACIA, protocol number PM_L_0051) have been published elsewhere. ${ }^{67}$ Briefly, 100-150 consecutive consenting patients with suspected ACS were enrolled from 39 hospitals across Australia between November 2005 and May 2006 ( $n=3402$ ), with a 12-month follow-up in $99.7 \%$ of the cohort achieved by June 2007. Patients presenting with ACS secondary to other processes such as major trauma or surgery, were excluded. Ethics committee approval was provided at each site. Informed consent was obtained from all patients except those who died before consent was sought and permission for access to medical records for these patients was granted by the local ethics committees. Late events were centrally adjudicated. This analysis is confined to patients with a final diagnosis of either ST-segment elevation (STEMI; $\mathrm{n}=683$ ) or non-STEMI (NSTEMI; $\mathrm{n}=947$ ), regardless of survival status, as determined by the enrolling site, and subsequently confirmed by central adjudication of electrocardiograms and biomarkers using standard accepted definitions.

\section{Clinical factors and invasive management}

We collected variables focusing on time to presentation, time to treatment, treatments administered and demographic and clinical factors known 
to be important for short- and long-term risk stratification and risk adjustment.

Time to presentation among patients with STEMI was categorised as $<3 \mathrm{~h}, 3-6 \mathrm{~h}$ and $>6 \mathrm{~h}$. Reperfusion therapy for such patients was classified as no reperfusion, timely fibrinolysis ( $\leqslant 30 \mathrm{~min}$ from presentation), delayed fibrinolysis (>30 min from presentation), timely primary percutaneous coronary intervention (PPCI; $\leqslant 90$ min from presentation) and delayed PPCI (>90 min from presentation). Timely early invasive management was defined as patients undergoing coronary angiography within $72 \mathrm{~h}$ of presentation during the acute hospital stay, regardless of the need for transfer between acute care hospitals. Delayed intervention reflected angiography during the index hospitalisation but $>72 \mathrm{~h}$, while no early invasive management included those receiving no angiography or outpatient angiography. Patients undergoing revascularisation based on angiographic data predating the index admission were excluded. The use and adherence to antithrombotic treatment, HMG-CoA reductase inhibition, angiotensin converting enzyme inhibitors/angiotensin receptor antagonists and $\beta$ blockers were evaluated at discharge. Patients not prescribed treatments based on stated contraindications (eg, $\beta$ blockers and asthma, allergy to aspirin) were excluded. Late loss of adherence was defined as the proportion of patients initially prescribed four or five guideline treatments who where alive and taking three or fewer treatments at 6-months' follow-up.

\section{Treatment effects, 30-day and 12-month event rates and costs}

We estimated treatment effects, where possible, from large-scale randomised clinical trials or meta-analyses as they provide robust and unbiased estimates of relative treatment effect size (table 1).

Loss of adherence was modelled as a "lack of benefit" except for invasive management, where omission was permitted to be associated with possible benefit.

A contemporary completely untreated subgroup of patients with MI was not available in the literature. Therefore, we used the observed 30-day and 12-month mortality and MI and/or stroke rates for those patients receiving invasive management and four or more guideline recommended treatments adjusted for median age (65 years), gender (male) and median GRACE score (score 139) (C statistic 0.82) within the ACACIA registry as the estimate for mortality and recurrent ischaemic events in an optimally managed population.

\section{Effects of omission of proven treatments}

To estimate the effect of the omission of each treatment, treatment delay or loss of compliance on overall mortality, we used the inverse of the treatment effect of each (risk associated with omission (a)) multiplied by the proportion of patients not receiving that treatment (proportion of population at risk (b)). We then multiplied this figure by the overall case-event rate for optimally treated patients (the absolute risk (c)) and then by a population of 10000 (absolute number of people (d)). ${ }^{11}$

For example:

(a) Aspirin provides a $24 \%$ reduction in mortality, so the excess mortality risk associated with omitting aspirin: $1 / 0.76=1.32$

(b) Assuming the observed rate of aspirin omission was $10 \%$ or 0.1 ;

(c) Using the observed 12-month case fatality rate for optimally managed patients of $5 \%$ or 0.05 ;

(d) Assuming 10000 presentations with MI per year.
It follows that the absolute number of potential excess deaths resulting from omission of aspirin can be calculated as " $((\mathrm{a} \times \mathrm{b})+$ $(1-b)-1) \times c \times d "$ or $((1.32 \times 0.1)+(1-0.1)-1) \times 0.05 \times$ $10000=16$ deaths.

The following modifications to this basic analysis were made. Since patients with STEMI and NSTEMI represent mutually exclusive groups and the impact of delay in presentation, mode of reperfusion and receipt of timely reperfusion on clinical events is confined to STEMI, we modelled these separately over 30 days, and then combined for the assessment of secondary prevention treatments on events from 30 days to 12 months.

We modelled treatments cumulatively using the Mant-Hicks cumulative relative-benefit approach. ${ }^{12}$ To provide an estimate of the individual contribution of suboptimal delivery of care for each individual treatment, an average weighted effect for the number of patients in each group at risk (not receiving treatment) was also calculated. The average excesses in events due to delay, suboptimal adherence to guidelines in prescribed treatment and non-compliance were then summated, and presented as total excess deaths for STEMI, NSTEMI during the first 30 days and secondary prevention up to 12 months, as well as their individual components.

Since a similar process applied to the prescription of treatments at discharge and non-adherence at 6 months would lead to an exceedingly large number of combinations without power to confidently estimate non-treatment rates (91 possible patterns of non-compliance $=8281$ possibilities), we modelled discharge treatments in the sequence of aspirin, statin treatment, clopidogrel, angiotensin converting enzyme inhibitors/ angiotensin receptor antagonists and $\beta$ blockers, with the proportion of "at-risk" patients representing those discharged alive on four, three, two, one and no treatments. Lack of adherence was modelled as a single rate across the entire population, with its effects modelled as a "lack of use," rather than an increased risk beyond the known magnitude of effect of agents as observed in some studies. ${ }^{10}$ In addition, non-adherence was applied to all treatments except aspirin and statin use, as these agents were rarely discontinued in the audit data. The resultant effect of putative novel treatment that was assumed to provide a further $10 \%, 20 \%$ and $30 \%$ relative risk reduction in 12 -month clinical events, where this benefit was confined to selected indications such as patients already optimally treated, was contrasted with a $10-30 \%$ relative reduction in mortality resulting from a "system-wide" improvement in care delivery. Discrepancies between the individual figures and totals reflect combined risks among patients and the effects of rounding.

\section{Sensitivity analysis}

We undertook multiway sensitivity analyses employing the analysis-of-extremes methodology, where the upper and lower confidence bounds for each variable were used when available (for treatment effect and case fatality rate), while using $\pm 20 \%$ when confidence bounds were not available, with the lower bounds of treatment effects truncated at 1.0, to prevent the modelling of event-free advantage for omission of care.

\section{RESULTS}

Among the 3402 patients enrolled in the ACACIA study, 1744 had a final diagnosis of MI, and a further 114 were excluded owing to described contraindications, leaving 1630 patients for this analysis. The mean age was 64.7 years, while $28.6 \%$ were female, $24.3 \%$ were diabetic and $37.0 \%$ had a prior history of prior coronary artery disease. Overall, by 30 days and 12 months, 
Table 1 Literature-based estimates of relative increase in events related to the non-receipt of various components of acute coronary syndrome care

\begin{tabular}{|c|c|c|c|c|}
\hline Events & $\begin{array}{l}\text { Relative } \\
\text { risk }\end{array}$ & $\begin{array}{l}\text { Upper } \\
\text { estimate }\end{array}$ & $\begin{array}{l}\text { Lower } \\
\text { estimate }\end{array}$ & Reference \\
\hline \multicolumn{5}{|l|}{ Presentation } \\
\hline No delay & 1 & & & 23 \\
\hline Delay 3-6 h & 1.21 & 1.45 & 1 & 23 \\
\hline Delay $6>\mathrm{h}$ & 1.47 & 1.76 & 1.18 & 23 \\
\hline \multicolumn{5}{|l|}{ Reperfusion } \\
\hline PPCI optimal & 1 & & & 23 \\
\hline $\mathrm{PPCl}$ delay & 1.24 & 1.49 & 1 & 23 \\
\hline Lysis optimal & 1.1 & 1.32 & 1 & 23 \\
\hline Lysis delay & 1.28 & 1.52 & 1.02 & 23 \\
\hline None & 1.47 & 1.76 & 1.18 & 23 \\
\hline \multicolumn{5}{|l|}{ Invasive management } \\
\hline Timely invasive & 1 & & & \\
\hline Delayed invasive & 1.10 & 1.21 & 0.75 & 21 \\
\hline None & 1.22 & 2.00 & 0.75 & 24 \\
\hline \multicolumn{5}{|l|}{ Pharmacotherapy } \\
\hline GP Ilb/llla inhibition & 1.09 & 1.18 & 1 & 25 \\
\hline ASA & 1.32 & 1.43 & 1.22 & 26 \\
\hline Statin & 1.45 & 1.56 & 1.35 & 27 \\
\hline Clopidogrel & 1.41 & 1.79 & 1.11 & 28 \\
\hline ACE inhibition or ARB & 1.19 & 1.37 & 1.03 & 29 \\
\hline$\beta$ Blocker & 1.30 & 1.45 & 1.18 & 30 \\
\hline
\end{tabular}

Risk associated with omission calculated as the inverse of the clinical trial based estimate or relative benefit.

$A R B$, angiotensin receptor blocker; $A C E$, angiotensin converting enzyme; $A S A$, acetylsalicylic acid (aspirin); GP, glycoprotein; PPCl, primary percutaneous coronary intervention.

71/1630 (4.4\%) and 155/1630 (9.5\%) had died, respectively, while recurrent MI was seen in 104/1630 (6.4\%) and 168/1630 (10.3\%), respectively, at the same time points. Table 2 shows presentation delays, treatment delays and the use of treatments during the acute in-hospital stay, as well as adjusted event rates up to 30 days and between 30 days and 12 months among all patients, and those receiving optimal treatments. Table 1 presents estimates of the effects of omission associated with evidencebased treatments obtained from the literature.

\section{Impact of early management of STEMI}

For patients presenting in a timely manner, receiving timely reperfusion and early invasive management with concomitant glycoprotein IIb/IIIa inhibition, the age, gender and GRACE risk score adjusted 30-day mortality and recurrent $\mathrm{MI} /$ stroke rates were very low, $0.6 \%(0.2-2.0 \%)$ and $5.8 \%(3.5-9.7 \%)$, respectively (table 2). However, these patients represented only 13.5\% of the STEMI population. Imputing the relative benefits associated with timely presentation, early reperfusion, mode of reperfusion, subsequent early invasive management and glycoprotein IIb/IIIa inhibition, to the remaining population of patients with STEMI yields a further 23 lives saved and 213 non-fatal events prevented per 10000 presentations (table 3). Table 3 presents components of this benefit. Only $4 \%$ of the deaths $(1 / 23)$ are attributable to receiving fibrinolysis rather than PCI as reperfusion therapy in a timely manner.

\section{Impact of the early management of NSTEMI}

Among optimally treated patients with NSTEMI, receiving early invasive management and intravenous glycoprotein
IIb/IIIa inhibition, the observed adjusted 30-day mortality and recurrent ischaemic event rates were 2.5\% (0.9-7.0\%) and 5.2\% (2.6-10.0\%), respectively (table 2). Optimal management of these patients was seen in $12.4 \%$ of patients. Extending timely use of invasive management and glycoprotein IIb/IIIa inhibition to the entire population would be associated with 43 lives saved and 55 recurrent events prevented among 10000 presentations. Table 3 presents components of this benefit.

\section{Impact of secondary prevention treatments}

Among patients discharged alive, $76.3 \%$ of patients were prescribed four or more guideline-recommended chronic pharmacotherapies, and by 6 months $22.4 \%$ of these patients were no longer adherent (taking three or fewer treatments). The observed adjusted mortality and recurrent ischaemic rates were $1.8 \%(1.1$ to $2.9 \%)$ and $4.1 \%(3.2-5.3 \%)$ from 30 days to 12 months, respectively (table 2). Ensuring more complete prescription and adherence to proven treatments to the entire population would be associated with a further 104 lives saved and 191 recurrent ischaemic events prevented per 10000 presentations (table 3). Figure 1 describes the observed adjusted-mortality and the model-projected rates associated with the increasing use of guideline-recommended treatments.

\section{Impact of novel therapeutic approaches}

Within this national audit, only $4.0 \%$ of all MI presented within $3 \mathrm{~h}$ of symptom onset and received timely reperfusion with either PCI or fibrinolysis for STEMI, or received early invasive management with glycoprotein IIb/IIIa inhibition in the context of NSTEMI, and were then discharged on four or five treatments with maintained late adherences to these treatments. Table 3 presents the benefits associated with a novel therapeutic approach yielding a further 10\%, 20\% and 30\% relative reduction in mortality and/or non-fatal ischaemic events among these optimally managed patients and all patients, regardless of the extent of concomitant treatment, by 12 months.

\section{DISCUSSION}

By drawing on data from randomised clinical trials and systematic reviews and combining these with contemporary Australian evidence regarding the application of such treatments, we have demonstrated that the potential gains that may be achieved with widespread application of current therapeutic approaches are much greater than those that may arise from future innovations in the management of MI. Among current recommendations, improving prescription of drugs at discharge and ensuring late adherence are likely to provide the greatest reductions in subsequent mortality and non-fatal ischaemic events. A greater absolute number of fatal and non-fatal ischaemic events are likely to be prevented by more complete application of any treatments as opposed to the choice between these treatments. Lastly, consideration of the costs relevant to the provision of care and subsequent events, may provide context for the design, implementation and resourcing of strategies for improving the quality of care of patients with ACS.

In extrapolating clinical research efficacy to an observed broader community, we draw upon two robust sources of data. First, randomised clinical trial data represent the best estimates of relative treatment efficacy, effectively eliminating clinical heterogeneity. However, the potential "absolute" impacts of such treatments on lives saved or events prevented are governed 
Table 2 Characteristics, application of treatments and outcomes observed in the ACACIA population

\begin{tabular}{|c|c|c|c|}
\hline Characteristics & $\begin{array}{l}\text { STEMI } \\
(\mathrm{n}=683)\end{array}$ & $\begin{array}{l}\text { NSTEMI } \\
\text { (n=947) }\end{array}$ & $\begin{array}{l}\text { All } \\
(n=1630)\end{array}$ \\
\hline Age (years), mean (SD) & $62.0(19.2)$ & $66.7(20.4)$ & $64.7(20.2)$ \\
\hline Male gender & $513(75.1)$ & $651(68.7)$ & $1164(71.4)$ \\
\hline Diabetes & $130(19.0)$ & $266(28.1)$ & $396(24.3)$ \\
\hline Dyslipidaemia & $310(45.4)$ & $550(58.1)$ & $860(52.7)$ \\
\hline Hypertension & $342(50.1)$ & $623(65.8)$ & $965(59.2)$ \\
\hline Current smoker & $227(33.2)$ & $216(22.8)$ & $443(27.2)$ \\
\hline Prior Ml & $92(13.5)$ & $258(27.2)$ & $350(21.5)$ \\
\hline Prior CABG & $21(3.1)$ & $150(15.8)$ & $171(10.5)$ \\
\hline Known CCF & $15(2.2)$ & $108(10.5)$ & $123(7.1)$ \\
\hline Creatinine clearance $\left(\mathrm{ml} / \mathrm{min} / 1.73 \mathrm{~m}^{2}\right)$, median (IOR) & $73.3(27.6)$ & $69.0(32.7)$ & $71.6(31.4)$ \\
\hline Prior CVA & $23(3.4)$ & $70(7.4)$ & $93(5.7)$ \\
\hline Presentation delay $<3 \mathrm{~h}$ & $486(71.2)$ & $508(53.6)$ & $994(61.0)$ \\
\hline Presentation delay $3-6 \mathrm{~h}$ & $84(12.3)$ & $163(17.2)$ & $247(15.2)$ \\
\hline Presentation delay $6+\mathrm{h}$ & $113(16.5)$ & $276(29.1)$ & $389(23.9)$ \\
\hline $\mathrm{PPCI} \leqslant 90 \mathrm{~min}$ & $105(15.4)$ & & \\
\hline $\mathrm{PPCl}>90 \mathrm{~min}$ & $187(27.4)$ & & \\
\hline Fibrinolysis $\leqslant 30 \mathrm{~min}$ & $137(20.1)$ & & \\
\hline Fibrinolysis $>30 \mathrm{~min}$ & $42(6.1)$ & & \\
\hline No reperfusion & $212(31.0)$ & & \\
\hline GP Ilb/llla inhibition used & $307(44.9)$ & $146(15.4)$ & $453(27.8)$ \\
\hline Angiography $\leqslant 72 \mathrm{~h}$ & $529(77.4)$ & $450(47.5)$ & $979(60.1)$ \\
\hline Angiography $>72 \mathrm{~h}$ & $83(12.2)$ & $229(24.2)$ & $312(19.1)$ \\
\hline No angiography & $71(10.4)$ & $268(28.3)$ & $339(20.8)$ \\
\hline Aspirin at discharge & $633(92.3)$ & $868(91.7)$ & $1501(92.1)$ \\
\hline Statin at discharge & $608(89.0)$ & $808(85.3)$ & $1416(86.9)$ \\
\hline Clopidogrel at discharge & $544(79.6)$ & $605(63.9)$ & $1149(70.5)$ \\
\hline$\beta$ Blocker at discharge & $538(78.8)$ & $672(71.0)$ & $1210(74.2)$ \\
\hline ACEI/ARA at discharge & $540(79.1)$ & $661(69.8)$ & $1201(73.6)$ \\
\hline \multicolumn{4}{|l|}{ All patients, \% (95\% Cl) } \\
\hline Adjusted 30-day death (\%)* & $1.8(1.0$ to 3.2$)$ & $2.4(1.4$ to 3.8$)$ & \\
\hline Adjusted 30-day re-Ml/stroke (\%) & $6.7(3.5$ to 12.8$)$ & $6.8(5.0$ to 8.9$)$ & \\
\hline Adjusted 30 days to 12 months death (\%) & & & $3.5(2.5$ to 4.7$)$ \\
\hline Adjusted 30 days to 12 months re-Ml/stroke (\%) & & & $3.9(2.9$ to 5.2$)$ \\
\hline \multicolumn{4}{|l|}{ Optimal management广, \% (95\% Cl) } \\
\hline Adjusted 30-day death (\%) & $0.6(0.2$ to 2.0$)$ & $2.5(0.9$ to 7.0$)$ & \\
\hline Adjusted 30-day re-MI/stroke (\%) & $5.8(3.5$ to 9.7$)$ & $5.2(2.6$ to 10.0$)$ & \\
\hline Adjusted 30 days to 12 months death (\%) & & & $1.8(1.1$ to 2.9$)$ \\
\hline Adjusted 30 days to 12 months re-Ml/stroke (\%) & & & 4.1 (3.2 to 5.3$)$ \\
\hline
\end{tabular}

by their uptake and the baseline risk of the population, both of which cannot be evaluated within the protocol-driven trial designs that often employ stringent inclusion and exclusion criteria. Second, clinical registries seeking to enrol consecutive patients and evaluate the application of care within a realistic clinical context provide good documentation of use and risk, but are less good at evaluating efficacy, owing to unmeasured biases. Consequently, a hybrid approach, incorporating both sources and encompassing the cost implications, has the possible strength of informing "value" choices that must be made before "investing" in the onward development and delivering of any treatment strategy. ${ }^{11}$ In this regard, investment in research and strategies directed at the better application of guidelineadvocated pharmacotherapies and ensuring adherence is likely to provide the greatest future reductions in mortality and nonfatal ischaemic events in clinical care. This observation is conservative, given the relatively short time frame (12 months) considered in this study.

Our analysis also suggests that there is more to be gained by the broader application of these treatments to those patients who are currently not receiving care, as opposed to the choice between treatments among those who are. The greatest potential gains appear to reside with extending reperfusion therapy to all patients, increasing access to angiography and more complete application of secondary prevention treatments. Such observations do not seek to ignore the many challenges and barriers in applying evidence-based care to many patients with increased clinical complexity and frailty. Instead, it argues for research focused on overcoming these challenges. However, these observations are in stark contrast to the current research and development focus on the choice between primary PCI and fibrinolysis in STEMI and the numerous "non-inferiority" 
Table 3 Potential opportunities for (a) lives saved and (b) non-fatal events prevented and components of these benefits (with sensitivity analysis) through better application of treatments and possible innovations

\begin{tabular}{|c|c|c|c|c|}
\hline & $\begin{array}{l}\text { Deaths per } \\
10000\end{array}$ & $\begin{array}{l}\text { Range in sensitivity } \\
\text { analysis }\end{array}$ & $\begin{array}{l}\text { Recurrent MI or } \\
\text { stroke per } 10000\end{array}$ & $\begin{array}{l}\text { Range in sensitivity } \\
\text { analysis }\end{array}$ \\
\hline Total events: STEMI & 23 & 2 to 60 & 213 & 24 to 527 \\
\hline Delayed presentation & 6 & 1 to 13 & 60 & 14 to 127 \\
\hline Fibrinolysis rather than PPCl & 1 & 0 to 5 & 12 & 0 to 45 \\
\hline Delayed PPCI & 3 & 0 to 10 & 38 & 0 to 92 \\
\hline Delayed fibrinolysis & 1 & 0 to 3 & 11 & 1 to 26 \\
\hline No reperfusion & 7 & 3 to 17 & 83 & 25 to 161 \\
\hline Delayed invasive management & 0 & 0 to 1 & 2 & 0 to 4 \\
\hline No invasive management & 1 & 0 to 7 & 5 & 0 to 27 \\
\hline Total Events: NSTEMI & 43 & 0 to 177 & 55 & 0 to183 \\
\hline Delay invasive management & 4 & 0 to 10 & 3 & 0 to 8 \\
\hline No invasive management & 16 & 0 to 87 & 11 & 0 to 67 \\
\hline No GP & 21 & 0 to 59 & 40 & 0 to 96 \\
\hline $\begin{array}{l}\text { Total events: secondary prevention } \\
\text { treatments }\end{array}$ & 104 & 27 to 266 & 191 & 61 to 605 \\
\hline Lack of prescription & 46 & 16 to 101 & 121 & 36 to 229 \\
\hline Non-adherence & 58 & 11 to 165 & 69 & 24 to 376 \\
\hline Putative novel therapy & Optimal* & All $\dagger$ & Optimal & All \\
\hline $10 \%$ Reduction & 1 & 34 & 4 & 96 \\
\hline $20 \%$ Reduction & 3 & 67 & 9 & 192 \\
\hline $30 \%$ Reduction & 4 & 101 & 13 & 288 \\
\hline
\end{tabular}

*Optimal—for patients with STEMI: reperfusion, early invasive management and GP Ilb/lla inhibition; for patients with NSTEMI: early invasive management and GP Ilb/llla inhibition; for secondary prevention: four or five guideline recommended treatments at discharge and adherent at 6 months; $\uparrow$ All-a benefit that applies to the entire population.

GP, glycoprotein; Ml, myocardial infarction; NSTEMI, non-ST-segment elevation myocardial infarction; PPCl, primary percutaneous coronary intervention; STEMI, ST-segment elevation myocardial infarction.

studies evaluating various antithrombotic strategies among patients presenting with non-ST-segment elevation ACS. ${ }^{13-16}$ Resources may be better directed towards evaluating the factors limiting the application of care to the broader and generally higher-risk clinical community, and confirming the absolute benefits among such patients.

These potential opportunities should also be contrasted with the possible gains provided by innovation such as new reperfusion approaches, refinements in technologies such as drug-eluting stents and emboli protection devices, and stem cells for myocardial repair. ${ }^{3}{ }^{17} 18$ These approaches are very costly to develop and to implement, but their benefits are often being restricted to relatively limited indications or small subgroups of patients. Similarly, the relatively restrictive inclusion and exclusion criteria employed in many modern trials limit their generalisability and therefore uptake by the broader community. Furthermore, it is noted that despite the evolution in ACS management, few treatments in more recent years have singularly reduced mortality by a magnitude of $10 \%$. In addition, given the highly selected populations of patients included in these clinical trials, the generalisability of the small mortality benefits observed to the broader population remains
Figure 1 Age, gender and GRACE score observed mortality and model projected mortality rates associated with the use of an increasing number of secondary prevention treatments.

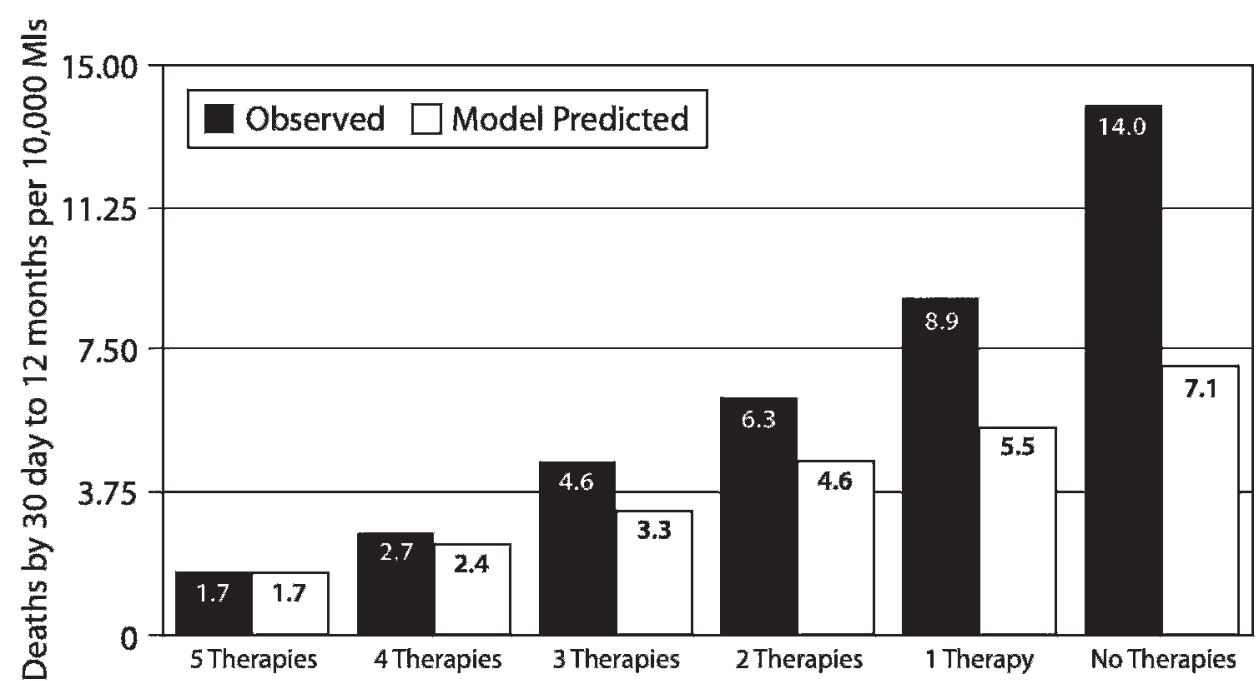


in question. In contrast, system-wide improvements in care delivery, such as standardised discharge tools, have provided 12month mortality benefits well in excess of this relative magnitude of a novel treatment. ${ }^{19}$

\section{Limitations}

Several limitations should be considered. First, a problem inherent in any modelling undertaking-this analysis describes possible rather than actual gains, and depends on the assumptions made. Such characteristics are unavoidable in any forward-looking projection, and estimates have been either conservative or based on robust data.

Second, the age, gender and GRACE score-adjusted base rates for 30-day and 12-month mortality for patients treated optimally are drawn from a relatively small number of patients, leading to greater uncertainty. However, these estimates may well underestimate the risk since registry evidence documents the bias towards the more complete use of treatments among lower-risk patients. ${ }^{20}$ In addition, we have confined the benefits of invasive management to 30-day outcomes, potentially undervaluing the impact of invasive management on late events. This is conservative as the confidence bounds are broadest for this intervention. ${ }^{21}$ Nevertheless, assuming that the benefit of invasive management persists to 12 months does not result in gains that exceed those seen with secondary prevention. Furthermore, while varying these rates does impact the absolute numbers of events attributable to various "omissions of care", the relative relationship between quality improvement and innovation remains unchanged.

Third, it is assumed that the relative effects of treatments are applicable to those to whom it is not applied and that these treatment effects remain independent of each other. Several studies have demonstrated that patients not receiving treatments are more often those at increased risk, who potentially stand to achieve a greater absolute benefit. ${ }^{20}{ }^{22}$ Furthermore, while there is likely to be diminishing return from the cumulative use of all the guideline treatments, this effect is accounted for by the methods of the analysis. While true interaction between treatments is not accounted for here, subgroup analyses of clinical trials have rarely shown true interactions between treatments, other clinical risk factors and treatment effects. Hence, while this approach represents a relatively "conservative" perspective, more rigorous evaluation of the impact of treatments among underserved high-risk groups is greatly needed.

\section{CONCLUSIONS}

Within the context of current Australian management of ACS, quality improvement initiatives directed at the prescription and persistence of secondary prevention treatments are likely to have the greatest potential for the reduction of both mortality and recurrent events. Optimising access to any form of reperfusion and invasive investigation is also likely to provide greater mortality benefits than novel treatments and strategies that further refine these treatments or strategies.

Funding: The ACACIA study was sponsored by Sanofi-Aventis Australia. The sponsors have viewed the manuscript but have not modified the content.

Competing interests: None declared.

Ethics approval: The ACACIA study was approved by the Flinders Medical Centre ethics committee and at each of the 39 enrolling sites.

Patient consent: Patient consent received.

Provenance and peer review: Not commissioned; externally peer reviewed.

\section{REFERENCES}

1. Aroney CN, Aylward P, Kelly AM, et al. National Heart Foundation of Australia Cardiac Society of Australia and New Zealand Guidelines for the management of acute coronary syndromes 2006. Med J Aust 2006;184:supplement 1.

2. Antman EM, Hand M, Armstrong PW, et al. 2007 Focused Update of the ACC/AHA 2004 Guidelines for the Management of Patients With ST-Elevation Myocardial Infarction: a report of the American College of Cardiology/American Heart Association Task Force on Practice Guidelines: developed in collaboration with the Canadian Cardiovascular Society endorsed by the American Academy of Family Physicians: 2007 Writing Group to Review New Evidence and Update the ACC/AHA 2004 Guidelines for the Management of Patients With ST-Elevation Myocardial Infarction Writing on Behalf of the 2004 Writing Committee. Circulation 2008;117:296-329.

3. Gick M, Jander N, Bestehorn HP, et al. Randomized evaluation of the effects of filterbased distal protection on myocardial perfusion and infarct size after primary percutaneous catheter intervention in myocardial infarction with and without STsegment elevation. Circulation 2005;112:1462-9

4. Armstrong PW, Granger CB, Adams PX, et al. Pexelizumab for acute ST-elevation myocardial infarction in patients undergoing primary percutaneous coronary intervention: a randomized controlled trial. JAMA 2007;297:43-51.

5. Orlic D, Kajstura J, Chimenti $S$, et al. Bone marrow cells regenerate infarcted myocardium. Nature 2001;410:701-5.

6. Chew DP, Amerena J, Coverdale S, et al. Current management of acute coronary syndromes in Australia: observations from the acute coronary syndromes prospective audit. Intern Med J 2007;37:741-8.

7. Chew DP, Amerena JV, Coverdale SG, et al. Invasive management and late clinical outcomes in contemporary Australian management of acute coronary syndromes: observations from the ACACIA registry. Med J Aust 2008;188:691-7.

8. Eagle KA, Goodman SG, Avezum A, et al. Practice variation and missed opportunities for reperfusion in ST-segment-elevation myocardial infarction: findings from the Global Registry of Acute Coronary Events (GRACE). Lancet 2002;359:373-7.

9. Nallamothu BK, Bates ER, Herrin J, et al. Times to treatment in transfer patients undergoing primary percutaneous coronary intervention in the United States: National Registry of Myocardial Infarction (NRMI)-3/4 analysis. Circulation 2005:111:761-7.

10. Ho PM, Spertus JA, Masoudi FA, et al. Impact of medication therapy discontinuation on mortality after myocardial infarction. Arch Intern Med 2006;166:1842-7.

11. Ford ES, Ajani UA, Croft JB, et al. Explaining the decrease in U.S. deaths from coronary disease, 1980-2000. N Engl J Med 2007;356:2388-98.

12. Mant J, Hicks N. Detecting differences in quality of care: the sensitivity of measures of process and outcome in treating acute myocardial infarction. BMJ 1995;311:793-6.

13. Keeley EC, Boura JA, Grines CL. Primary angioplasty versus intravenous thrombolytic therapy for acute myocardial infarction: a quantitative review of 23 randomised trials. Lancet 2003;361:13-20.

14. Keeley EC, Boura JA, Grines CL. Comparison of primary and facilitated percutaneous coronary interventions for ST-elevation myocardial infarction: quantitative review of randomised trials. Lancet 2006;367:579-88.

15. Stone GW, McLaurin BT, Cox DA, et al. Bivalirudin for patients with acute coronary syndromes. N Engl J Med 2006;355:2203-16.

16. Ferguson JJ, Califf RM, Antman EM, et al. Enoxaparin vs unfractionated heparin in high-risk patients with non-ST-segment elevation acute coronary syndromes managed with an intended early invasive strategy: primary results of the SYNERGY randomized trial. jama 2004;292:45-54.

17. Laarman GJ, Suttorp MJ, Dirksen MT, et al. Paclitaxel-eluting versus uncoated stents in primary percutaneous coronary intervention. $N$ Engl J Med 2006;355:1105-13.

18. Primary versus tenecteplase-facilitated percutaneous coronary intervention in patients with ST-segment elevation acute myocardial infarction (ASSENT-4 PCI): randomised trial. Lancet 2006;367:569-78.

19. Eagle KA, Montoye CK, Riba AL, et al. Guideline-based standardized care is associated with substantially lower mortality in Medicare patients with acute myocardial infarction: the American College of Cardiology's Guidelines Applied in Practice (GAP) Projects in Michigan. J Am Coll Cardiol 2005;46:1242-8.

20. Fox KA, Anderson FA Jr, Dabbous $\mathrm{OH}$, et al. Intervention in acute coronary syndromes: do patients undergo intervention on the basis of their risk characteristics? The Global Registry of Acute Coronary Events (GRACE). Heart 2007:93:177-82.

21. Bavry AA, Kumbhani DJ, Rassi AN, et al. Benefit of early invasive therapy in acute coronary syndromes: a meta-analysis of contemporary randomized clinical trials. J Am Coll Cardiol 2006;48:1319-25.

22. Alexander KP, Roe MT, Chen AY, et al. Evolution in cardiovascular care for elderly patients with non-ST-segment elevation acute coronary syndromes: results from the CRUSADE National Quality Improvement Initiative. J Am Coll Cardiol 2005; 46:1479-87.

23. Boersma $\mathbf{E}$. Does time matter? A pooled analysis of randomized clinical trials comparing primary percutaneous coronary intervention and in-hospital fibrinolysis in acute myocardial infarction patients. Eur Heart J 2006;27:779-88.

24. Neumann FJ, Kastrati A, Pogatsa-Murray G, et al. Evaluation of prolonged antithrombotic pretreatment ("cooling-off" strategy) before intervention in patients with unstable coronary syndromes: a randomized controlled trial. JAMA 2003;290:1593-9.

25. Boersma E, Harrington RA, Moliterno DJ, et al. Platelet glycoprotein Illb/llla inhibitors in acute coronary syndromes. Lancet 2002;360:342-3. 
26. Collaborative meta-analysis of randomised trials of antiplatelet therapy for prevention of death, myocardial infarction, and stroke in high risk patients. $B M J$ 2002;324:71-86.

27. LaRosa JC, He J, Vupputuri S. Effect of statins on risk of coronary disease: a metaanalysis of randomized controlled trials. JAMA 1999;282:2340-6.

28. Sabatine MS, Hamdalla HN, Mehta SR, et al. Efficacy and safety of clopidogrel pretreatment before percutaneous coronary intervention with and without glycoprotein IIb/IIla inhibitor use. Am Heart $J$ 2008;155:910-7.

29. Rodrigues EJ, Eisenberg MJ, Pilote L. Effects of early and late administration of angiotensin-converting enzyme inhibitors on mortality after myocardial infarction. Am J Med 2003;115:473-9.

30. Freemantle $\mathbf{N}$, Cleland $\mathrm{J}$, Young $\mathrm{P}$, et al. beta Blockade after myocardial infarction: systematic review and meta regression analysis. BMJ 1999;318:1730-7.

\section{Images in cardiology}

\section{Percutaneous surgery for mitral valve disease}

A 62-year-old man presented with progressive exercise limitation for the previous 18 months. He was found to have prolapse of the middle scallop of the posterior mitral valve leaflet and associated severe mitral regurgitation. He had had coronary artery by-pass grafting 4 years previously. All the grafts were patent, but because the internal mammary artery graft ran immediately behind the sternum on computed tomography angiography, he was quoted a high mortality rate for repeat surgery.

We offered him percutaneous mitral valve repair using the MitraClip device (Evalve Inc, California, USA). The MitraClip is

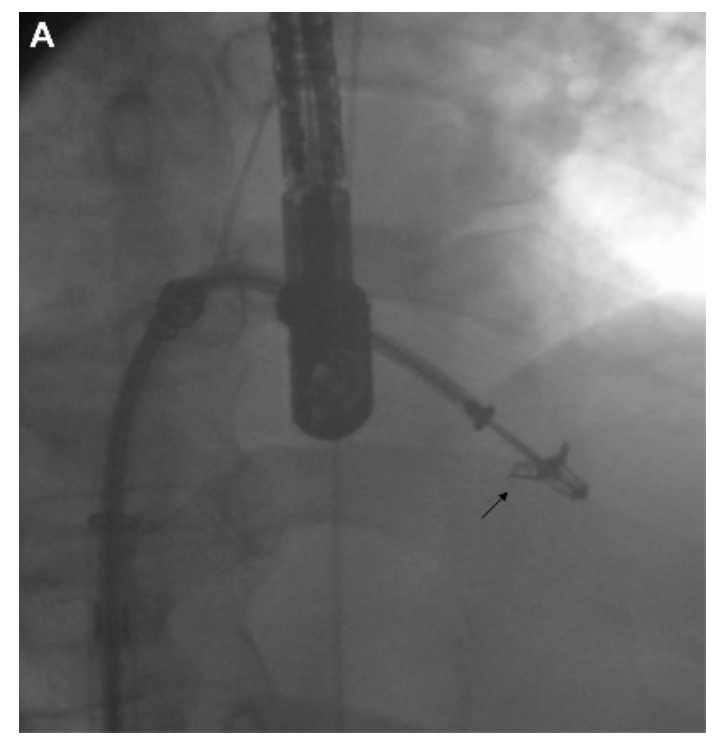

RAO view. The MitraClip (arrowed) is shown opened in the left ventricular cavity. A transoesophageal echocardiography probe is in the centre of the picture.

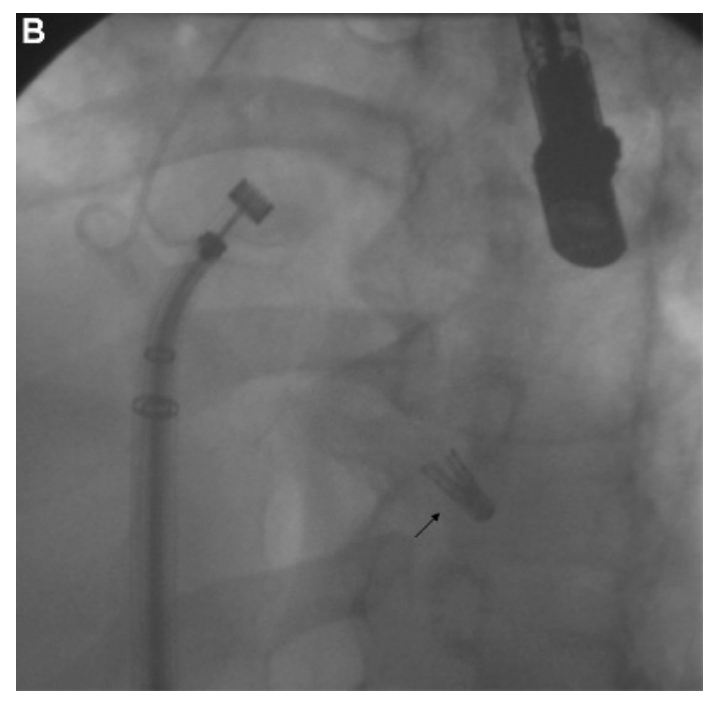

LAO view. The MitraClip (arrowed) has been delivered and the delivery sheath has been withdrawn to the right atrium. A pigtail catheter is visible in the ascending aorta.

introduced using a $24 \mathrm{~F}$ sheath via the femoral vein into the left atrium using a trans-septal puncture under transoesophageal echocardiographic control. The clip is then manoeuvred through the mitral orifice, opened, pulled back towards the left atrium thereby capturing the mitral leaflets and deployed, leaving a "double-barrelled" mitral orifice.

The two images show (panel A) the MitraClip in position in the left ventricle before deployment; and (panel B) the MitraClip in position after release. In this instance, the mitral regurgitation disappeared angiographically having been severe pre-operatively. The mitral valve area postoperatively was greater than $3 \mathrm{~cm}^{2}$.

\section{A L Clark, M F Alamgir, R K Nair, S T Thackray}

a.l.clark@hull.ac.uk

Provenance and peer review: Not commissioned; not externally peer reviewed. Heart 2009;95:1850. doi:10.1136/hrt.2009.167536 